\title{
IMPORTANT QUESTIONS OF COMPARATIVE STUDIES IN ASIAN COUNTRIES
}

\begin{abstract}
The issue of the "identity" of comparative education as a field of study or a discipline has been discussed for decades. Yet a kind of systematic structure that provides the basic principles for a coherent exposition of the field remains open. "Comparative education" is no longer conceived as an imaginary field's coherence but, rather in terms of distinct branches of comparative and international studies in education and their underlying issues. Such an understanding is fostered through a deepened awareness of the basic problems, and successive solutions, constitutive of the emergence and further conformations of the comparative approach in education and the social sciences. Thus, academic journal publications of the past decade to shape education policy research within an Asia-Pacific context have been analyzed. Facts of increasing research collaboration, growing policy evaluation research, and growing attention to higher education have been presented. Significant difference in research impact and diffusion between Asia-Pacific and American education policy studies has been shown. Perspectives for future research directions in education policy research in an Asia-Pacific context have been suggested.

Key words: education policy research, comparative studies, globalization, regionalization, Asia-Pacific region, international studies on education, neo-institutional theory, private tutoring, language education.
\end{abstract}

\section{INTRODUCTION}

Educational reforms in different countries come into the notice of researchers of this sphere, together with attempts to develop and provide implementation of effective educational strategies for successful development of countries. The study of educational strategies allows us to understand better modern problems in education for a certain country. To the researchers' mind, there is need for the comparative analysis of educational strategies in the world, at the same time the problem of the so-called "identity" or "individuality" of comparative pedagogy as a discipline has been discussed for many years. Nevertheless, a question about the type of systematic structure which provides base principles for logical and clear presentation of this sphere is opened. In J. Schriewer's opinion "comparative pedagogy" cannot be anymore perceived within the limits of unreal, fictitious coherences of this sphere, but must be perceived as clear branch of pedagogy and its issues (Schriewer, 2014). Such understanding arose as a result of the deep study of base problems of pedagogy, appearance and subsequent development of comparative approach in education and social sciences.

\section{THE AIM OF THE STUDY}

The aim of this article is to characterize directions of comparative researches in the countries of Asia, to distinguish the structural determining features of comparative studies, to observe a place and influence of neo-institutional theory on comparative researches. 


\section{THEORETICAL FRAMEWORK AND RESEARCH METHODS}

What was cross-cultural research before the appearance of cross-country researches? Frederic K. Tenbrak, a wellknown German sociologist, asked such a paradoxical question in his article in 1992. F. Tenbrak compares the "scientific cross-cultural comparing" to the "socially directed cross-cultural researches", and although he accents on ambiguity of this question, as a play on words, at the same time he specifies socio-historical terms and ontological vision, that entailed appearance of different styles of comparative and international researches, which follow absolutely different logic.

For our research we used scientific general methods which are main ways of studying scientific sources, and comparative-historical method for synchronic comparison of event in the same region.

RESULTS

Our analysis confirms the increasing number of researches devoted to tendencies in globalization and their influence on the national systems of education, and that fact put a neo-institutional theory in the center of many disputes of comparative pedagogy. Although a neo-institutional theory gives the clear approach to the understanding of the social, economic, political and educational phenomena, it has its own set of indefinite concepts, especially in the cultural aspects of comparative pedagogy. Contrasting conceptions of education from the point of globalization as well as the locally concentrated process, sometimes called "glocalization" influenced the comparative studies of the educational phenomenon. Neo-institutional theory is one of the directions of organizational theories, which embrace many disciplines of political science, economy, and sociology. In other words, neo-institutional theory is wider, than the specialized sphere of comparative education, and that is why, more difficult (Wiseman, Astiz \& Baker, 2014).

The characteristic feature of neo-institutional researches is that "something identified at a wider level is used for explanation of processes or phenomena at a narrower level and their analysis". Neo-institutionalism considers any organizations "as a free combination of the standardized elements", but do not as "a whole unit". In other words, homogeneity can be in some parts of the educational systems or establishments rather than in the system as a whole. It allows the great number of configurations of these standardized elements, based on the culture, context and individual actions.

We can say that comparative researches of educational sphere, which aim at determination of subsequent prospects of community development, are conducted not to attest the homogeneity of future cultures, educational establishments, and students. Their aim is to understand those unique and unusual ways which modern norms and expectations from an educational environment differentiate in culturally different societies. Some scientists use the different aspects of neo-institutional theory for explanation of both international trends in an educational policy and local adaptation, implementation of results, and thus turn to "free combination" of the set elements.

The analyzed materials allow us to distinguish "socio-logic" of international researches of reforms in education. The vivid example of comparative researches of education within the limits of sociological neo-institutionalism is Davies and Aurini's work about international educational corporations which are a part of the phenomenon of private tutoring. They give proofs, that international educational corporations provide the hybrid models of education, which are designed according to "institutional models", but also are combined by conditions of organizational level to support their competitiveness in the demanding market of educational services (Wiseman, Astiz \& Baker, 2014). 
Researches, which are executed in globo-logic pay attention to the fact that globalization requires comparison of the systems and strategies of national education in different countries. Moreover, one of advantages of cross-national comparisons is the study of progressive ideas and ways to solve general issues for countries all over the world. Beside practical advantage, comparison of educational strategies makes possible to produce knowledge, accepted for all countries (Wook Jeong, Ho Jun Lee, Seung Ho Lee, Eunjoo Wi, 2014).

Thus, the determining fact of modern researches of education is that tendencies in globalization more require comparisons of the national educational systems and strategies in the world. One of advantages of cross-national comparisons is an exchange of ideas and solutions for the study of general issues and challenges which countries face. As a result transfer of educational policy from one country to another becomes possible. That is why, practical advantage of comparative researches of educational strategies appears in producing knowledge that is valid and general for all countries (Jeong Ho Jun Lee, Seung Ho Lee, Eunjoo Wi, 2014).

Very often comparative researches which are conducted within the limits of neoinstitutional theory give advantage to widespread, cross-cultural analyses as a way to appeal to the institutional issues or to research of the educational phenomenon of a system level (Wiseman, Astiz \& Baker, 2014). For verification of results of researches and confirmation of efficiency of educational strategies, many researchers pay attention to Asian countries.

Very interesting, in our opinion, is the analysis of researches of educational strategies, which were carried out in the countries of the Asian region in the last few years. Our analysis of publications in the Asiatic countries showed that professional development of teachers comes into question as one of major questions of educational policies in the Asiatic countries. L. Darling-Hammond \& M. McLaughlin underline that educational strategies must contribute to the development of teachers' potential so that they could take responsibility for the studies of students, and for subsequent reformation of education in the correct direction (Darling-Hammond \& McLaughlin, 1995). Asian countries are not an exception: our analysis of researches allows us to select two basic questions which are examined in strategies of professional development. The first question is a design of strategies in accordance with the specific context of every Asian country. The developers of educational policy often face the necessity of strategic development of instruments of professional development for the unique context of every country. For example, the Asian countries have a tendency of introduction of IKT of technologies in pedagogical education, use of encouraging bonuses according to their pedagogical activity. In addition, the evaluation of teachers' professional activity in the Asian countries is considered an important question for their professional development (Wook Jeong, Ho Jun Lee, Seung Ho Lee, Eunjoo Wi, 2014).

The second important question in strategies of teachers' professional development is the discussion of globalization, and the basic interest lies in commercialization of higher education and internationalization of curriculums.

Plenty of comparative researches of educational industry point out that integration of educational structure, establishments, on-line curriculums, and educational policies does not mean integration of a personality's behavior or activity of establishments. Moreover, growing similarity in the national educational systems, curriculums, and educational activity is not synonymic to homogeneity. Often convergence of educational policies, curriculums and structures is explained by "externalization" and "internationalization" (Wiseman, Astiz \& Baker, 2014). A noticeable contrast is observed between the spread of the transnational 
standardized educational models and persistence in their varying in accordance with the socio-cultural peculiarities of a certain country.

The theory of the systems, as well as historical comparativism provide researchers of comparative pedagogy with an alternative mean of conceptualization of the world educational systems, which allow the isomorphism of structure, policies, curriculums, with observable diversification in these systems. An isomorphism is a process of assimilations in spite of terms, which in other cases cause diversification. An isomorphism can specify homogeneity in an educational structure, activity, but this is not the state of homogeneity which is achieved purposefully.

It should be taken into account that the various approaches to comparative researches from the point of different versions of neo-institutional theory are based on different social sciences and methodologies. Researchers which focus attention only on local issues or those, who light up cross-national differences do not "see an iceberg under a surface" (Anderson-Levitt, 2012). Butmany anthropological approaches to comparative researches require the use of macro/global and micro/local "lenses" for the study of the educational systems for more complete understanding of the educational phenomenon (Wiseman, Astiz $\&$ Baker, 2014).

The researches, carried out on local and macro levels have many advantages, they distinguish the unique phenomena and give proofs of efficient policies in different states, societies and establishments. They provide possibility to identify and analyze unique responses and resistance to imposing norms and actions. But weakness of localized and macro level comparative researches is in the fact that they limit possibility for researchers to summarize the conclusions, even at the presence of plenty of information about a certain situation.

In relation to the researches of the Asian scientists, our study allows us to draw a conclusion about their orientation on the analysis of actual changes in strategies for the development of higher educational establishments and their explanation of co-operation of the new state management and institutional isomorphism. Internationalization in education is also an important question for the Asian countries. Such attention became the result of internationalization of universities in the Asia and side effects from internationalization. K. H. Mok and X. Xu study how Chinese higher education tries to attain openness for an educational market (Mok \& Xu 2008).

The next important question which is lighted up in researches of the Asian scientists is an exposure of strategies in language education for the increase of national competence in the age of globalization. Many Asian countries declare English as official or second language. Importance of these skills was widely described in the Asian countries, and high results in the English tests definitely correlate with academic success and success in professional activity. The growth of interest to strategies in language education put forward the researches of questions of English teachers' training. For this purpose the Englishlanguage program for teachers, EFL/ESL programs come into question as main instruments to implement these strategies. W. Luo specifies that the policy of encouraging of the English-speaking teachers - native speakers in initial schools encounter the problems of actualization of ideal educational process in the real class room (Luo, 2007).

Another important aspect of researches of the Asian scientists is so-called shadow education, or private tutoring. It is a very actual theme due to a competition climate at the educational market and national idea of the importance of education for social and economic development of a country. In many Asian countries attempts to clarify how shortenings of domestic charges on private lessons were made. For this purpose some key measures were offered, including introduction of the out-of-school curriculums. Another 
question which relates to shadow education is an interrelation between private tutoring and formal education. M. Lee studies the history of shadow education in South Korea, and focuses attention on the attempts of government to change requirements for private tutoring (Lee, 2005). I. Mori, D. Baker came to the conclusion, that shadow education appears after the institutional changes in formal education and will be gradually integrated in a wider by its limits system of education (Mori \& Baker, 2010).

Comparison with researches of educational policy in America causes special interest. We consider that they are very interesting because they allow us to distinguish peculiar features of researches of educational policy in the Asian region. Moreover, it provides us with understanding of directions for the researches of such kind in the future.

It is interesting that in the American journals, devoted to educational policy of the country more attention is paid to the researches of the evaluation of policy efficiency than to other procedures, and quantitative methodology of researches is very noticeable. Six from ten researches of policy are concentrated on the evaluation of strategies in the Asian countries, and eight from ten - the American policy. More researches touch initial and middle school. However, the questions of higher school are becoming more topical in Asian countries.

In America and Asian countries there are such questions as teachers' professional development, quality of pedagogical education, curriculum for initial school teachers, teaching methods in pedagogical establishments, equal possibilities for education that are considered as most essential.

At the same time, in America the choice of schools appears to be the influential instrument of educational policy for reforming state education in education oriented to the user. It takes place because a competition among schools for parents can be the fundamental factor of improving the quality of education.

Among insignificant differences between American researches and researches in the Asian countries is the fact that American researches are mostly concentrated on the evaluation of efficiency of the certain programs of professional development. We draw attention to the fact that in the Asian countries researches focus in a greater degree on the description of certain examples of professional development. In researches of question of equal rights for education the American scientists try to estimate the effect from reforms of the certain curriculums and strategies in certain schools, at that time in the Asian countries attention is concentrated on the description of attempts of educational strategies directed to the reduction of this inequality (Wook Jeong, Ho Jun Lee, Seung Ho Lee, Eunjoo Wi, 2014).

\section{CONCLUSIONS}

Thus, the conducted analysis testifies to the increasing number of researches devoted to globalization tendencies and their influence on the national systems of education. At the same time, there is an increase in discussions related to the importance of neo-institutional theory for comparative pedagogy. There is an influence of neo-institutional theory on comparative researches and vice versa. Comparative researches of educational industry are conducted from the point of "epistemo-logic" (social query of researches), "socio-logics" (or international researches of reforms in industry of education), "globo-logic" (study of the transnational phenomena and all-embracing educational phenomenon). The analysis of comparative researches of the Asian scientists shows great attention of scientists to the influence of globalization on strategies of development of educational industry, private tutoring, language education, that is conditioned by the necessity of reformation of the Asian educational systems in globalization.

As the theme for our further researches we refer the analysis of international comparative organizations activity in the era of globalization. 


\section{REFERENCES}

1. Anderson-Levitt, K. (2012). Complicating the concept of culture. Comparative education, No. 48 (4), p. 441-454.

2. Darling-Hammond, L., \& McLaughlin, M. W. (1995). Policies that support professional development in an era of reform. Phi Delta Kappan, No. 76 (8), p. 597-604.

3. Lee, M. (2005). Major issues of university education policy in Hong Kong. Asia Pacific Education Review, No. 6 (2), p. 103-112.

4. Luo, W. (2007). A study of native English-speaking teacher programs in elementary schools in Taiwan. Asia Pacific Education Review, No. 8 (2), p. 311-319.

5. Mori, I., \& Baker, D. (2010). The origin of universal shadow education: What the supplemental education phenomenon tells us about the postmodern institution of education. Asia Pacific Education Review, No. 11 (1), p. 36-48.

6. Mok, K. H., \& Xu, X. (2008). When China opens to the world: A Study of transnational higher education in of Zhejiang. China. Asia Pacific Education Review, No. 9 (4), p. 393-408.

7. Schriewer, J. (2014). Neither orthodoxy nor randomness: differing logics of conducting comparative and international studies in education. Comparative Education, Volume 50, No. 1, p. 84-101.

8. Wiseman, A., Astiz, M. \& Baker, D. (2014). Comparative education research framed by neo-institutional theory: a review of diverse approaches and conflicting assumptions. Journal of Comparative and International Education, Volume 44, No. 5, p. $688-709$.

9. Wook, J., Lee, Ho Jun, Seung, Ho Lee, Eunjoo, Wi. (2014). Shaping education policy research in an Asia-Pacific context. Seul : Education Research Institute, Seoul National University, p. 38. 